\title{
Forest and the city: A multivariate analysis of peri-urban forest land cover patterns in 283 European metropolitan areas
}

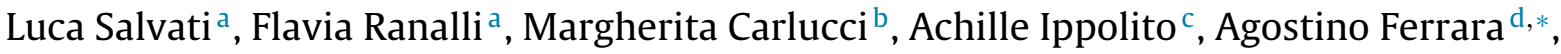 \\ Piermaria Corona ${ }^{\mathrm{e}}$ \\ a Council for Agricultural Research and Economics, Research Centre for the Soil-Plant System (CREA-RPS), Via della Navicella 2-4, I-00184 Rome, Italy \\ ${ }^{\mathrm{b}}$ Department of Social and Economic Sciences (DISSE), Sapienza University of Rome, Piazzale A. Moro 5, I-00185 Rome, Italy \\ c Department of Architecture and Design, Sapienza University of Rome, Via Flaminia 359, I-00196 Rome, Italy \\ d School of Agricultural, Forest, Food and Environmental Sciences, University of Basilicata, Viale dell'Ateneo Lucano 10, I-85100 Potenza, Italy \\ e Council for Agricultural Research and Economics, Forestry Research Centre (CREA-SEL), Via Santa Margherita 80, I-52100 Arezzo, Italy
}

\section{A R T I C L E I N F O}

\section{Article history:}

Received 1 April 2016

Received in revised form 8 July 2016

Accepted 16 September 2016

\section{Keywords:}

Urban atlas

Sprawl

Socioeconomic context

Landscape metrics

Europe

\begin{abstract}
A B S T R A C T
Heterogeneous definitions of urban areas and poorly homogenized forest data at the country scale have hampered the comparative assessment of peri-urban forest structure in developed countries. The present study investigates selected landscape characteristics of peri-urban forests in 283 metropolitan areas in Europe controlling for the role of the local context and regional suburbanization trends. Using landscape metrics derived from Urban Atlas maps (a Copernicus/GMES initiative providing a comprehensive land-use assessment of European cities $>100,000$ inhabitants), significant differences in peri-urban forest structure were detected under five European regions. Specific class metrics (percent forest area, mean patch size, perimeter-to-area ratio) were correlated with urban morphology, landscape and territorial indicators. On average, forest cover is larger in northern and southern European metropolitan areas. Forest patch size increases from western to eastern Europe, with more regular patch shapes in central and eastern regions and less regular shapes in the rest of Europe. Forest class area increases with the area of discontinuous, medium-density settlements. Forest patch size increases with the average patch size of discontinuous dense urban fabric. Our evidence outlines a 'sprawl model' shaping fringe landscapes characterized by discontinuous urban settlements mixed with fragmented - but possibly well protected - forest patches.
\end{abstract}

(C) 2016 Published by Elsevier Ltd.

\section{Introduction}

Urbanization is increasingly affecting environmental quality and ecosystem patterns at the global scale (Piorr et al., 2011; Wu, 2013). Changes in the use of land depend on place-specific factors shaping the spatial organization of metropolitan areas and are in turn influenced by the socioeconomic and planning context, at both national and regional scales (Hall and Hay, 1980; Couch et al., 2007; Turok and Mykhnenko, 2007). For example, Europe in the industrial age was characterized by a small number of urban centres dominating (more or less) vast rural areas (European Environment Agency (EEA), 2006a). In the past century, cities grew mainly along the access routes, railroads and waterways (Antrop, 2004).

\footnotetext{
* Corresponding author.

E-mail address: agostino.ferrara@unibas.it (A. Ferrara).
}

After World War II, with the growing use of cars, cities expanded into rural areas, creating dispersed settlements and fragmenting natural and agricultural landscapes. Especially during the last three decades, European landscapes have been experienced drastic transformations impacting soil, water, biodiversity and rural communities (Zitti et al., 2015). According to Piorr et al. (2011) more than a quarter of land in Europe is affected by urbanization. The expanding Wildland-Urban Interface (WUI) reflects the growing anthropogenic pressure on fringe land where cities, agriculture and forestry are competing for space (European Environment Agency (EEA), 2006a; Tavares et al., 2012).

Forests and green areas surrounding cities have been considered key components of urban ecosystems, being managed for centuries especially in central Europe. Public green spaces were considered an appropriate response to the decreasing quality of life in expanding industrial cities (Konijnendijk et al., 2006). The notion of 'urban forest', originally proposed in the United States, appeared for the first time in Europe at the end of the 1970s (Ricard, 2005). This 